\title{
Sociopragmatic Differences and Behaviors in the Use of WhatsApp in Virtual Classrooms at a Public College of Education in Ghana
}

\author{
Solomon Dadzie \\ ORCID: https://orcid.org/0000-0003-4322-6926 \\ Komenda College of Education, Komenda, Ghana \\ Salomey Horsu \\ ORCID: https://orcid.org/0000-0002-0614-5169 \\ St. Peter's Senior High School, Nkwatia-Kwahu, Ghana \\ Emmanuel Kyei* \\ ORCID: https://orcid.org/0000-0002-8966-5468 \\ Akenten Appiah-Menka University of Skills Training and Entrepreneurial Development, Ghana \\ *Corresponding Mail: okyekye09@gmail.com
}

\begin{abstract}
Copyright resides with the author(s) in terms of the Creative Commons Attribution CC BY-NC 4.0. The users may copy, distribute, transmit and adapt the work, but must recognize the author(s) and the East African Journal of Education and Social Sciences
\end{abstract}

\begin{abstract}
This study sought to establish how tutors at Komenda College of Education engaged students in virtual classroom during the COVID-19 pandemic. The study employed a qualitative approach through the descriptive design. Data was 462 conversations between tutors and students through the WhatsApp messaging application. To ensure anonymity and confidentiality, all personal names and other details were removed. The study established that while tutors posted more messages than students, messages of the tutors were made up of instructions, commands and directions. Students addressed their tutors with high respect. Female students sent more and longer messages and utilized more emoticons than their male counterparts. Contracted and nonconventional forms of speech were very common in students' WhatsApp chats with their tutors. Both the tutors and students used persuasive words (e.g. please, and kindly) as a way of gaining approval from the other party. Verbal fillers in the WhatsApp group chats performed two macro-functions: interpersonal and textual. Based on the findings, the following recommendations were made. First, institutions of higher learning should provide the instructional support to teachers and students on how to minimize or maximize their own speech differences while engaged in a virtual classroom. There should be pedagogical models in virtual classrooms that allow learners and facilitators to engage in more informal ways. Finally, for an effective online learning to take place, tutors and students should appropriately accommodate each other.
\end{abstract}

Keywords: Code switching; online teaching; second language; virtual classroom; WhatsApp

How to cite: Dadzie, S., Horsu, S. and Kyei, E. Sociopragmatic Differences and Behaviors in the Use of WhatsApp in Virtual Classrooms at a Public College of Education in Ghana. East African Journal of Education and Social Sciences 2(4), 130-135. Doi: https://doi.org/10.46606/eajess2021v02i04.0137.

\section{Introduction}

Covid-19 pandemic has forced teachers and students to spend more time using online material for learning. As a result, institutions of higher learning are currently undergoing a mass "migration" away from the traditional face-to-face education towards online learning. Online learning is a system that makes use of electronic media, specifically the internet, to facilitate access to 
materials and maximized interaction with content Online learning allows students to learn through the use of such platforms as Zoom, Teams, Veeva, and Google Classroom. WhatsApp is among a plethora of internet platforms that educational institutions have utilized throughout the COVID-19 pandemic period. It is a messaging application with numerous functions such as group messaging, text messaging, audio messaging and video calling. It is used in educational activities for several reasons: (1) it is simple to use; (2) it consumes less package data; and (3) it has numerous beneficial functions such as group chat, audio message, video call, and voice note (Raad, 2020).

In Ghana, the COVID-19 pandemic caused higher education institutions to implement emergency online teaching and learning to ensure continuity of academic work (Mensah, Blankson, Loglo \& Freeman, 2021). As schools were closed down, virtual learning emerged as the most effective pedagogical strategy for teachers seeking to connect with their students. The online tools mostly used included Zoom, Google Meet, Learning Management Systems (LMS), SMS text messaging, tele (audio) conferencing and WhatsApp.

Numerous studies in Ghana (e.g. Appiah, 2016; Henaku, 2020) examined the virtual learning and established that online teaching occurs in a very poor state in the country. Students are compelled to study online despite their inability to do so effectively. According to Tabiri, Jones-Mensah, Fenyi and Asunka (2021), online language learning is affected by numerous technological challenges including availability, accessibility, affordability and delivery. In Ghana, many lecturers continue to struggle to comprehend and engage with the online tools in order to enhance the teaching and learning process (Mensah, Blankson, Loglo \& Freeman, 2021). Sadly, traditional classroom instruction has been perceived to be more successful than online instruction (see Darkwa \& Antwi, 2021). Therefore, this study sought to establish (a) the social differences in the Use of WhatsApp Messages, (b) Sociopragmatic Behaviors in WhatsApp Groups and (c) how tutors and students accommodated each other in WhatsApp group chats in virtual classrooms.

\section{Review of Literature Theoretical Underpinnings}

This study was underpinned by the Communication Accommodation Theory which stipulates that speakers adapt their speech to their communication interlocutors (West \& Turner, 2010). Stated differently, communication can be mediated and accommodation tendencies are more apparent. As a result, an individual may minimize or emphasize his or her own speech differences with an interlocutor throughout a conversation. This presupposes a degree of speech accommodation in consideration of the communication interlocutor(s), which may be utilized for educational contexts. In line with this theory, this study analysed how the students may minimize or maximize their own speech differences with their tutors while engaged in a virtual classroom.

\section{Related Literature and Studies}

A number of studies (e.g. Appiah, 2016; Darkwa \& Antwi, 2021; Henaku, 2020) investigated the effectiveness of online teaching and learning before and during the COVID-19 pandemic in Ghana. Darkwa and Antwi (2021), for instance, compared classroom learning effectiveness before and during the COVID-19 pandemic in terms of course content, pedagogical approaches, interactivity, assessment, feedback and evaluation procedures. The study revealed that traditional or conventional classroom learning was perceived to be more effective than online learning. Henaku (2020) revealed that college of education students experienced internet connectivity problems and financial difficulty due to high cost of internet bundles and devices. Appiah (2016) assessed the influence of WhatsApp on the study habit among University students in the Kumasi Metropolis of Ghana and established that majority of participants indicated that using WhatsApp had an unimaginable impact on their academic pursuits.

Studies (e.g. Campbell \& Park, 2008; Zelenkauskaite \& Herring, 2006; Ling, 2005; Oksman \& Rautiainen, 2002) revealed that language use is contextualized by social elements such as culture, age, status, community, tradition, religion, power and gender. Ling (2005) found that females are more active and pragmatic SMS users than males, that females send longer text messages than males and that the females' use of emoticons or 'smiley' face icons is more prevalent than males'. Similarly, Zelenkauskaite and Herring (2006) established that women utilized emoticons and other textual representations of smile and laughter more frequently than men. Oksman and Rautiainen (2002) argued that computer-mediated messages serve as a "virtual fraternity" more among young folks than the old ones and that text messaging is more 
actively used by young people than old folks in many countries. Campbell and Park (2008) concluded that people have different conceptualizations of the mobile telephone and suggested further research to investigate the extent to which members of different cultures use the mobile phone.

\section{Research Methodology}

\section{Research Design}

The study employed the qualitative approach using a descriptive design due to the nature of data (WhatsApp messages). The researchers conducted a subjective evaluation of the content of the text data via a systematic categorization procedure involving coding and the identification of themes or patterns.

\section{Population and Sampling Procedure}

The study was carried out at Komenda College of Education, a public tertiary learning institution in Ghana. Researchers purposively involved only four English Language tutors and 150 second year regular students who were on the WhatsApp groups of the four English Language tutors in the college. The data from this study were 462 conversations between tutors and students through the WhatsApp messaging application.

\section{Statistical treatment of data}

The researchers took screenshots of the WhatsApp messages and used them for the analysis. The data was analyzed manually to establish trends in communication as guided by the objectives of the study.

\section{Ethical Considerations}

The researchers contacted the group administrators who in turn told the group about the intention of the researchers to use their chats for research purposes only. The group members unanimously agreed before the researchers retrieved the messages from the various administrators. To ensure anonymity and confidentiality, the researchers removed all personal names and other details.

\section{Results and Discussions}

This section presents findings and discussion in respect of the formulated research questions.

\section{Social Differences in the Use of WhatsApp Messages}

The first objective was to establish social differences between students and tutors in the WhatsApp posts. Out of 462 messages posted in the four groups, the four tutors posted 205 messages while the 150 students posted only 257 messages. Contrary to the claim by Oksman and Rautiainen (2002) that computer-mediated messages serve as a "virtual fraternity" more among young folks than the old ones, this study found that tutors posted more and lengthier messages than students. The fact that the older (tutors) used computer-mediated messages more than the young folks might be due to their (tutors') role as facilitators.

It was also revealed that the tutors' messages were composed of instructions, commands and directions. This finding implies that tutors were not only superior to their students, but also had significant power over them in the communicative event. Another indicator of the power difference was the way students addressed their tutors. Typically, the students began their addresses to tutors with such phrase as "Please Sir." Afful and Mwinlaaru (2012) explain that addressing lecturers with the titles Sir and Madam shows a high degree of respect. The implication is that students normally adapt their speech with the tutors, highlighting the conventional student-teacher relationship and/or the asymmetrical relationship.

In terms of sex, it was revealed that females sent more and longer messages than males. Particularly, females posted 152 while males posted 105 out of 257 messages. Additionally, female students utilized more emoticons than their male counterparts. This finding corroborates Zelenkauskaite and Herring's (2006) finding that women are more likely than males to utilize emoticons and other textual representations of smiling and laughter. This finding implies that there are social differences in the use of WhatsApp messages with respect to the interlocutors.

\section{Sociopragmatic Behaviors in WhatsApp Groups}

The second objective was to establish sociopragmatic behaviors in group WhatsApping between tutors and students in virtual classrooms. The study found that contracted forms were very common in students' WhatsApp chats with the tutors. Contracted forms refer to abbreviated words formed by combining two words and removing certain characters, which are replaced with an apostrophe. Examples of contracted words found in the data included don't, didn't, can't, l've and admin. The contracted form is in Chang and Swales' (1999) extracted list of informality features. Secondly, non-conventional forms of words such as 
uwc for you are welcome, de for the, tnx for thanks, buh for but, yh for yeah, and ok for okay were established. These forms were used by students even as they responded to or addressed tutors.

The study further revealed some English-Akan codeswitching elements which may have sociopragmatic undertones by the interlocutors as seen below:

Ive not been able to join for once mpo

Ive not been able to join for once even (linear glossing)

[l've not been able to join even ones.]

Yes de raining dia charlie no be easy oo

Yes the raining as for friend not be easy oo (linear glossing)

[Really, the rain is not easy, my friend.]Poor network paaaa

Poor network very (linear glossing) [Very poor network]

Oh sir ...... am not benefiting koraa hmmmm

Oh sir .......am not benefiting at all hmmmm (linear glossing)

[Oh sir, ...am not benefiting at all, hmmmmm.]

Some of the codeswitching examples are illustrated in Figures 1 and 2:

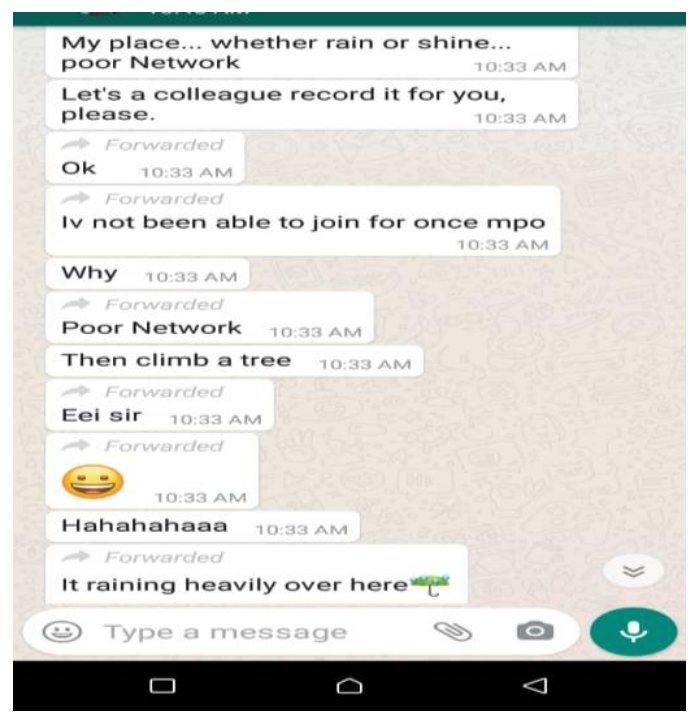

Figure 1: WhatsApp Conversations A

The code switching (e.g. "yes, de raining dia Charlie no be easy oo") can be termed as marked ones because the interlocutors did so for indexicality purposes. Indexicality refers to the features of a language that directly refer to the circumstances or context of an utterance. As a requirement for those who apply for admissions to various colleges of education in Ghana, they should be able to speak and write the Ghanaian languages offered by a particular college of their choice. Hence, at Komenda College of Education, the students learn the Akan language as well, despite the use of English as a medium of instruction and other purposes. It is, therefore, possible that students who code switched were aware that most of their target groups, the tutors and students, understood their switches. This explains why most of the students code switched using the Akan language. The students' codeswitching was to show their belongingness and solidarity to the group. This type of codeswitching conforms with Myers-Scotton (1993)'s Markedness Model. According to this model, "as speakers come to recognize the different Right and Obligation (RO) sets possible in their community, they develop a sense of indexicality of code choices for these Right and Obligation sets" (Myers-Scotton, 1993, p. 88). Because of this, a speaker who is a socialized member of his bilingual or multilingual speech community is aware of an underlying set of rules that determine why he should choose one code rather than another to the extent that whether he follows the rules or breaks them, he is in effect making a statement about the Right -Obligation set that he wishes to be in force between him and the addressee(s).

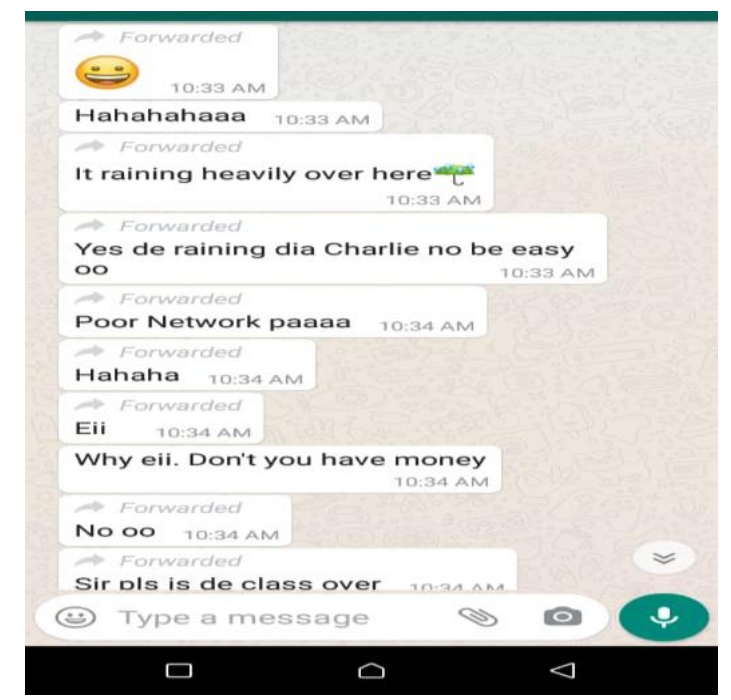

Figure 2: WhatsApp Conversations B

\section{How Tutors and Students Accommodated Each Other}

The third objective was to establish how tutors and students accommodated each other in whatsApp group chats. The results show that students and tutors accommodated each other in a number of 
ways. First, both the tutors and students used persuasive words (e.g. please, and kindly) as a way of gaining approval from the other party. Another way was the use of approval or agreement signals (e.g. okay, alright sir, thank you, yeah and wow). These words could help a speaker ascertain whether his/her addressee is in agreement with him or her or not. This is in line with the two concerns raised in Gile and Ogay's (2007) Communication Accommodation Theory (CAT): (1) the behavioral changes that people make to attune their communication to their partner(s); and (2) the extent to which people perceived their partner as appropriately attuning to them. There is no record of conversation stopping-words in the group chats. These words were avoided because the interlocutors did everything possible to adjust their speech to their partners. The last evidence of the application of CAT is the use of some emoticons to show agreement. Some of these emoticons included handshake images, folding of fingers, raising the thumb finger, laughing, etc. Figures three four and five illustrate the emoticons used.

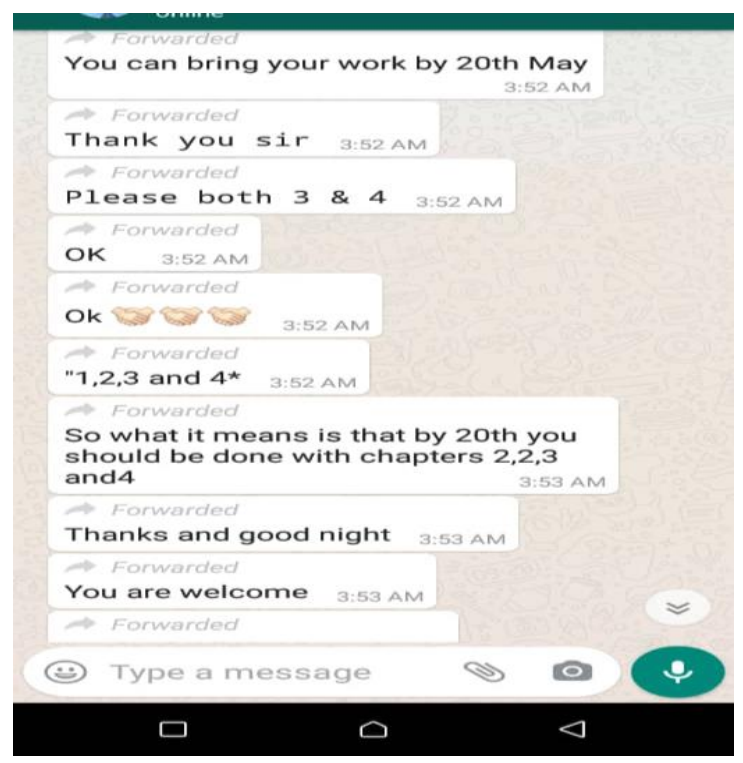

Figure 3: WhatsApp Conversations C

Furthermore, the study revealed other linguistic resources such as pragmatic markers, discourse markers or verbal fillers. Examples of these markers are Eii, Ah, Oh, Yeah, Ok and Wow. Pragmatic markers function in different linguistic domains or functional-semantic components. These markers or fillers were used to show surprise, to show agreement, to indicate what other members of the group are saying or to express excitement. Verbal fillers in the WhatsApp group chats performed interpersonal functions, signaling the relationships.
The interlocutors also used verbal fillers for textual functions such as to initiate or close discourse, to serve as a turn-holding device, to indicate a new topic or topic shift, to signal transitions in the discourse and to repair one's own discourse. This finding agrees with Brinton (1996) who distinguished two macro-functions of verbal fillers, namely: interpersonal functions and textual functions.

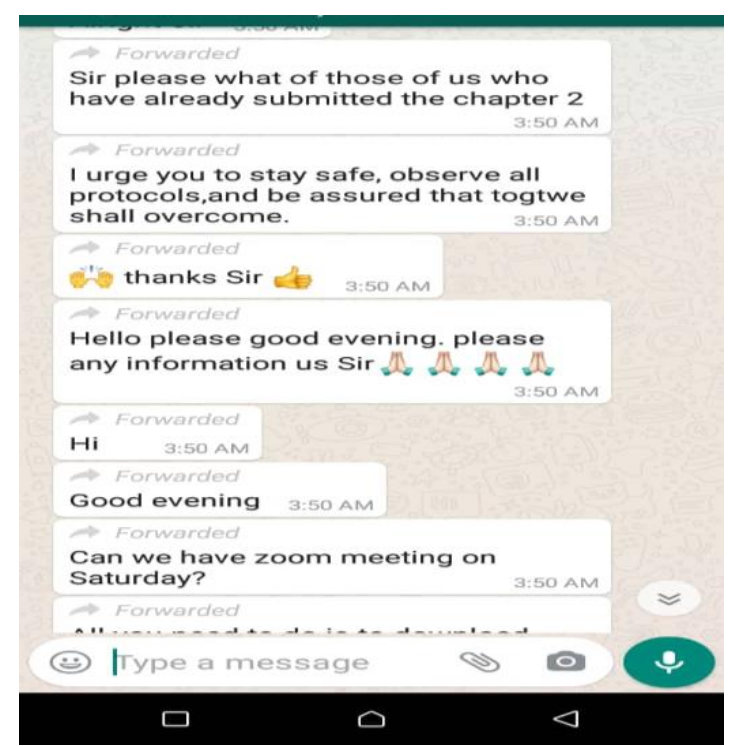

Figure 4: WhatsApp Conversations D

\section{Conclusions and Recommendations}

\section{Conclusion}

Tutors posted more messages than students. Messages of the tutors were made up of instructions, commands and directions. Students addressed tutors politely. Female students sent more and longer messages than male students and utilized more emoticons than their male counterparts. Students used non-conventional forms of words such as uwc for you are welcome, de for the, tnx for thanks, buh for but, yh for yeah, and ok for okay even as they responded to or addressed tutors. English-Akan codeswitching elements were used for indexicality purposes.

Students and tutors accommodated each other in a number of ways. First, both the tutors and students used persuasive words (e.g. please, and kindly) as a way of gaining approval from the other party. Second, there was the use of pragmatic markers ( discourse markers or verbal fillers) such as okay, eii, ah, alright sir, thank you, yeah and wow, and emoticons such as handshake images, folding of fingers, raising the thumb finger and laughing to mark approval or agreement, surprise or excitement. Finally, verbal fillers in the WhatsApp 
group chats performed two macro-functions: interpersonal and textual.

\section{Recommendation}

The study recommends that institutions of higher learning should provide the instructional support to teachers and students on how to minimize or maximize their own speech differences while engaged in a virtual classroom. There should be pedagogical models in virtual classrooms that allow learners and facilitators to engage in more informal ways. Finally, for an effective online learning to take place, teachers and students should appropriately accommodate each other.

\section{References}

Afful, J. B. A., \& Mwinlaaru, I. N. I. (2012). When sir and madam are not: Address terms and reference terms students use for faculty in a Ghanaian university. Sociolinguistic Studies, 6(3), 491.

Appiah, M. K. (2016). Influence of WhatsApp on study habit of university students in Ghana. International Journal of Research in Economics and Social Sciences, 6(3), 280292.

Brinton, L. J. (1996). Pragmatic markers in English: Grammaticalization and discourse functions; Berlin and New York, Mouton de Gruyter.

Campbell, S. W., \& Park, Y. J. (2008). Social implications of mobile telephony: The rise of personal communication society. Sociology compass, 2(2), 371-387.

Chang, Y. Y. \& Swales, J. (1999). Informal elements in English academic writing: Threats or opportunities for advanced non-native speakers? In C. Candlin \& K. Hyland (Eds.). Writing: texts, processes and practices (pp. 145-167). London: Longman.

Darkwa, B. F., \& Antwi, S. (2021). From classroom to online: Comparing the effectiveness and student academic performance of classroom learning and online learning. Open Access Library Journal, 8(7), 1-22.

Giles, H. \& Ogay, T. (2007). Communication Accommodation Theory. In B. B. Whaley, \& S. Wendy (Eds.). Explaining Communication: Contemporary theories and exemplars. Mahwah, NJ: Lawrence Erlbaum.
Henaku, E. A. (2020). COVID-19 online learning experience of college students: The case of Ghana. International Journal of Multidisciplinary Sciences and Advanced Technology, 1(2), 54-62.

Ling, R. (2005). The sociolinguistics of SMS: An analysis of SMS use by a random sample of Norwegians. In R. Ling \& P. Pedersen (Eds.), Mobile communications: Renegotiation of the social sphere (pp. 335-349). London: Springer.

Mensah, E. A., Blankson, I. A., Loglo, F. S., \& Freeman, E. (2021). Emergency Remote Teaching and Learning (ERTL) During COVID19: The Ghana Communication Technology University Experience. In Handbook of Research on Inequities in Online Education During Global Crises (pp. 321-339). IGI Global.

Myers-Scotton, C. (1993). Social Motivations for Code Switching: Evidence from Africa. Oxford: Clarendon Press.

Oksman, V. \& Rautiainen, P. (2002). Perhaps it is a body part. How the mobile phone became an organic part of the everyday lives of children and adolescents. In J. Katz (ed.) Machines that becomes us (pp. 293-308). New Brunswick, NJ: Transaction Publishers.

Raad, B. (2020). The Role of E-Learning in Covid19. International Journal of Creative Research Thought, 8(3), 3135-3138.

Tabiri, M. O., Jones-Mensah, I., Fenyi, D. A., \& Asunka, S. (2021). Challenges of online learning of English/French language in higher education in Ghana. Journal of Language and Linguistic Studies, 18(1).

West, R. \& Turner, L. H. (2010). Introducing communication accommodation theory analysis and application (4th ed.). New York: McGraw-Hill.

Zelenkauskaite, A. \& Herring, S. C. (2006). Gender encoding of typographical elements in Lithuanian and Croatian IRC. In F. Sudweeks \& C. Ess (Eds.), Proceedings of cultural attitudes towards technology and culture, Murdoch, Australia: Murdoch University Press. 